\title{
DesmedidAs fRONTEIRAS NA RELAÇÃo Sul-Sul
}

\section{MeAsureless bORDERS IN THE SOUTH-SOUTH RELATION}

\section{Estefânia Francis Lopes ${ }^{1}$}

\section{DOI: 10.11606/issn.1981-7169.crioula.2017.137247}

RESUMO: O presente artigo se propõe a focalizar os diálogos presentes no livro Desmedida: Luanda, São Paulo, São Francisco e volta, do escritor angolano, Ruy Duarte de Carvalho. Diálogos entre Brasil e Angola estabelecidos por meio da literatura, antropologia, música e relatos de viagens. Apontamos na construção textual como o autor, ao querer conhecer mais de perto o Brasil, que sempre esteve presente em seu imaginário, seja por meio das artes ou notícias, acaba por (re)encontrar Angola.

ABSTRACT: The present article has the purpose to focus the dialogues present in the book Desmedida: Luanda, São Paulo, São Francisco e volta by the Angolan writer Ruy Duarte de Carvalho. Dialogues between Brazil and Angola are established through literature, anthropology, music and travel reports. It is pointed out in the textual development the way the author, intending to get to know Brazil closer - which has always been in his imaginary, either by arts or news, ended up finding (again) Angola.

PALAVRAS-CHAVE: Diálogos; Brasil; Angola; Literatura; Música.

KEYWORDS: Dialogues; Brazil; Angola; Literature; Music.

1 Mestre em Estudos Comparados de Literaturas de Língua Portuguesa 
A "identificação pela via do arrepio", expressão utilizada - por José Luís Cabaço (CABAÇO, 2006, p. 40) tomada E de empréstimo de Ruy Duarte de Carvalho, é o móvel que me leva, como brasileira, a desenvolver algumas reflexões sobre Desmedida: Luanda, São Paulo, São Francisco e volta (2010) na senda do diálogo que recapitula a compreensão de passados, enfoca o presente e projeta futuros angolanos e brasileiros.

Segundo entendemos, o diálogo que o escritor, antropólogo e cineasta angolano estabelece com o território brasileiro se faz pela via da literatura, principalmente, mas não só. A música, o jornalismo e mesmo a vivência nos espaços contribuem para a narrativa que se quer livro e se projeta em um improvável filme. Neste quase diário de campo, ao escrever sobre os brasileiros, Ruy Duarte de Carvalho questiona-se: o que ele, sendo estrangeiro, naturalizado angolano, pode saber sobre o Brasil? Muitos são os caminhos propostos e, sob esse particular, singularidades, fronteira e sertão formam uma tríade temática que percorre a narrativa e leva o leitor por caminhos, "carreiras e picadas".

Percebe-se no texto de Carvalho que ele, ao querer situar Angola e o Brasil no mundo, se volta para o continente irmão, com "um sentimento de filho pródigo ciente daquilo que enquanto pessoa deve ao Brasil pelo que desde muito cedo na vida o Brasil Ihe deu a ler, a ouvir, a aprender, a ver e a imaginar" (CARVALHO, 2010, p. 397). Para Ruy Duarte a identificação se deu pela via da admiração. Ao apreender a brasilidade e percorrer o rio das crônicas, da ficção e da sociedade, vai montando um mosaico de informações, "causos" e experiências entre São Paulo, o Sertão nordestino e Luanda. 
Ao indicar pistas e ao mesmo tempo despistar, a narrativa de Desmedida vai sendo construída a partir de referências a livros que vão ao encontro do autor, por diálogos imaginários e reais - como a conversa entre o Saci-pererê e o escritor francês Blaise Cendrars (p. 47), ou ainda seus possíveis relatos das viagens de encontro aos pastores do sul, e sobretudo ao amigo Paulino (a partir da segunda parte) - e por experiências às margens do rio São Francisco de ontem e de hoje.

A primeira frase do livro, ao começar com reticências seguidas de um "complicando logo, que é para depois não causar estranheza", já indica os caminhos sinuosos da escrita elaborada por meio de "repetições, variações e simetrias, acasos, encontros e convergências" (CARVALHO, p. 20). No início do capítulo 12, por exemplo, o texto pede "atenção ao narrador", pois esse se encontra num momento de folga, retido pela chuva, "numa estação propícia à deriva", onde "a divagação é inevitável" (p. 163).

Os lugares e as leituras pelos quais o autor transita nos levam a revisitar o passado colonial, o qual, segundo Carvalho, faz com que, para pensarmos sobre Angola, tenhamos que pensar o Brasil e vice-versa, assim como, indispensavelmente, refletir também sobre o passado português. Entre tráficos de mercadorias e pessoas em que holandeses e portugueses disputaram os dois territórios, um trânsito intenso foi gerado entre os países. Tanto angolanos vieram para o Brasil, como brasileiros foram parar em Angola.

Mesmo com histórias diferentes tanto antes das independências como depois, o escritor chama a atenção para como, "embora sem dúvida cada um à sua maneira", os futuros de 
Angola e Brasil são ao mesmo tempo comuns e diferenciados por terem sido tocados pela expansão ocidental, como mostra o trecho a seguir,

Fico-me pelas interrogações que a viagem me suscita e, para poder também eu seguir em frente, inscrevo tudo nessa aritmética e cômoda evidência de que todos nós, angolanos e brasileiros, negros, índios, brancos ou de qualquer outra marca, somos todos hoje, produto do fenômeno colonial ou filhos da expansão ocidental. [...] Existimos todos, hoje, na decorrência de uma colonização que foi dando sumiço àqueles que de maneira como viviam não tinham maneira de resistir, servimo-nos da mesma língua oficial, invocamos lusofonias de hoje que já foram lusotropicalismos antes, somos todos do hemisfério sul [...]. (CARVALHO, p. 251-252, grifo do autor)

\section{O espaço e o tempo dinamizados}

O sertão é o pensamento que a gente forma dele.

Mas dá mesmo para contar com o que vem de fato ter ao nosso encontro, [...] uma revista avulsa [...] veio assegurar-me que o tempo e o espaço são irmãos gêmeos do destino, que o tempo é que faz a singularidade de um lugar. E que a arquitetura é a escrita do tempo. (Ruy Duarte de Carvalho)

Na ficção de Guimarães Rosa encontram-se as paisagens familiares para Ruy Duarte, assim como as personagens 
"de que ele tratava, gente de matos e de grotas, de roças e capinzais" (CARVALHO, p. 108). Personagens com características próximas das pessoas com quem o autor angolano manteve contato e acompanhou, por muito tempo, no sul de Angola. Dessa forma, na viagem que faz ao Brasil para reencontrar as paisagens literárias de Guimarães Rosa e Euclides da Cunha, o rio São Francisco e o Sertão vão sendo reconfigurados pelo seu olhar, pelas suas leituras e experiências.

Ao longo do texto de 401 páginas, tanto o rio quanto o sertão vão sendo definidos, e, algumas vezes, o espaço é aproximado às paisagens de Angola. O "Velho Chico" e o sertão são um só corpo que entrelaça os sujeitos que vivem nas e das suas margens, como ilustra o trecho a seguir,

Mal dei pelo rio, em Januária, mas em nenhum lugar outro, do que vi e pisei, senti tanto as marcas e a presença, não as do curso das águas e do traçado das margens, mas a da goma glandular, colada aos corpos, de gerações afins a um lugar. Não tanto, assim, a dimensão de um portentoso curso de água, mensurável, trabalhável, transponível, mas antes a de um deus fluvial que é o eixo e é o texto de um universo a que se dá um nome e onde colhe a dimensão de uma ideia e dos ecos que Ihe conferem a insondável espessura do fundo, e a vaga desmedida da extensão de um cosmos. Estou a falar do sertão. (CARVALHO, p. 121)

Rio e sertão configurados na desmedida do tempo e do espaço, ou seja, entre passados com origens remotas e um futuro incerto, bem como entre fronteiras sem limites precisos, 
de paisagens que se confundem e/ou refletem o fictício e "não raro fictível da referência rosiana", em um cenário que se faz "extenso e múltiplo, contraditório e ambíguo, desconcertante, quase, até, às vezes" (CARVALHO, p. 123).

É a partir de uma espécie de explicitação de rol de leituras feitas desde cedo, que o texto informa-nos que, inicialmente, foi um sertão imaginário o primeiro contato do autor com essas paisagens brasileiras ainda lá "na idade de passar da puberdade para a adolescência" (CARVALHO, p. 339), quando lia tudo o que fosse ao seu encontro sobre o Nordeste brasileiro. Lins do Rego também figura entre os autores que ajudaram na formação das imagens emotivas, na "altura em que a consciência do mundo começa a demandar mais longe" (CARVALHO, p. 339). Quando finalmente se depara com o agreste real pergunta-se, "facas então: cadê?...". Embora não tenha encontrado à venda facas de cangaceiro, reconhece em Caruaru, Pernambuco, outro símbolo comum das "paisagens euclidianas": o couro de bode, e, assim, segue "cheirando, pelos sertões, com ele" (CARVALHO, p. 350).

Outrossim, entre os variados espaços referenciados na narrativa, ainda encontramos o deserto da Namíbia e o sertão nordestino, como também, Recife "grande e vasto", Olinda "patrimônio cultural da humanidade inteira", São Tomé e Angola, retratados pelo olhar estrangeiro nas gravuras de Frans Post, Cabo e São Paulo . Na cidade paulistana, onde se hospeda por um período, descreve tanto a paisagem urbana e caótica de uma cidade cosmopolita com seus sebos, centro histórico, edifícios e telhados de casas, como a paisagem rural do Estado, com suas plantações de café e fazendas 
com grandes casarões e personagens políticos e folclóricos. A cidade parece espelhar a desmedida do país, por ser, nas palavras do narrador,

Uma placa de articulações planetárias, rampa de lançamento ou plataforma orbital, onde podem ter origem, confundir-se e anular-se os destinos todos possíveis, todos os campos de articulação que configuram o curso do tempo na nossa exata época e determinam os sucessos da ordem e do controle, e as dinâmicas da relação, que impõem o balanço do rumo e do modo da aplicação, da prática e da reprodução de todas as determinações que servem à projeção abissal da modernidade ainda e sempre em expansão e confrontada cada vez mais com os seus próprios impasses [...]. (CARVALHO, p. 391)

Assim, sob o enfoque de Carvalho, a cidade fundada por padres jesuítas em 1554, à época banhada pelos riachos Anhangabaú e Tamanduateí que "desembocavam no largo e belo rio que era então o Tietê", permaneceu com "uma aparência colonial" até o século XIX. Sendo a mesma cidade que abrigou os Modernistas em 1922, movimento artístico do qual Blaise Cendrars teve uma relevante influência pela proximidade com os artistas envolvidos. Por conseguinte, em breve resumo histórico sobre a cidade, Blaise Cendrars, escritor suíço, e Richard Burton, cronista viajante, que depois de ocupar um cargo em Santos, passa a morar em São Paulo, representam o olhar estrangeiro europeu, com "exaltações exóticas", não só sobre o continente americano, mas também, sobre a África. Fi- 
guras históricas (entre tantas outras que aparecem no livro) por meio das quais foi possível a Ruy Duarte reformular questões e imagens sobre o Brasil, em sua "decifração obstinada".

\section{DECANTAR A BRASILIDADE}

A originalidade de Desmedida é o olhar do sul para o sul. Um projeto que intenta revelar "tudo o que há de complementaridades, de contiguidades e de simultaneidades entre o Brasil e Angola, desde a era da descoberta até à dos banditismos sociais que entram muito pelo século XX" (CARVALHO, p. 53). Para tal, o diálogo principal se dá com a literatura, mas não só. Segundo Ruy Duarte de Carvalho, o Modernismo buscou cantar a brasilidade, que estava ainda em formação, frente às mudanças da vida moderna. Assim como a prosa e a poesia modernistas, a música popular brasileira é destacada por Carvalho como relevante referência cultural no que se refere à compreensão do Brasil, e mesmo de identificação pelos angolanos.

Seja na propaganda das tardes de matinê com modinhas de Luiz Gonzaga, das quais Carvalho consegue "trautear trechos inteiros", seja nos versos compostos pelo jornalista David Nasser, "Nega do cabelo duro", que reminiscências da música aparecem em Desmedida, como evocações que indicam a presença da música brasileira em Angola.

Vale nos atermos sobre alguns pontos quanto à proximidade entre Angola e Brasil no plano cultural, que acabam por reverberar nas questões literárias e linguísticas dos respectivos países. Seguindo a reflexão de Maria Aparecida Santilli (2003, p. 17), mesmo que descompassados cronologicamen- 
te, os compassos históricos que Angola e Brasil viveram com a metrópole portuguesa, a partir de 1822, ano da independência brasileira, entraram no "ritmo cada vez mais compulsivo da história das relações humanas", e assim abreviaram "a marcha em direção à sincronia". O Brasil passa a ser visto como referência de possibilidade de autonomia política.

A partir das independências, Santilli (p. 18) ressalta a revisão necessária dos povos emancipados, período conhecido como apocalíptico, "porque vividos nos estremecimentos de passagem para outra visão, a da utopia do novo", ou seja, "o de problematizar a tradição europeia/portuguesa enquanto modelo que então se abalava, no patrimônio de uma herança comum". Dessa forma, os laços e diálogos estreitam-se principalmente entre os intelectuais angolanos, moçambicanos e cabo-verdianos. A literatura brasileira, mais especificamente do modernismo, do neorrealismo e do regionalismo do Nordeste, são referências para os escritores africanos que têm o português como língua em comum. Porém, não só a marca linguística motiva essa aproximação, como também as identificações sociais e culturais deixadas pelas conexões históricas entre os respectivos países que sofreram a colonização portuguesa reforçam o querer mirar-se ao que se considerava um "país irmão", e não à antiga Metrópole.

A música e a poesia brasileiras estavam presentes nas rádios angolanas desde a década de 1950, após a presença de grupos de teatro musical e de digressões realizadas por cantores de música popular brasileira, como Angela Maria, que permaneceu na lembrança dos angolanos. O grupo Jo- 
grais de São Paulo - formado por um quarteto e fundado na cidade paulistana por Ruy Affonso em 1955, que fez grande sucesso nos anos de 1950, 1960 e 1970 - chegou a inspirar a formação dos Jograis do Liceu, composto por estudantes secundaristas angolanos.

Para Marcelo Bittencourt (2008, p. 4), "as alianças, referências e aproximações" entre Angola e Brasil "nunca se romperam de todo, o que se comprova pelo sucesso de nossas músicas e telenovelas por lá". A primeira novela a ser emitida pela televisão angolana, Gabriela, baseada no romance homônimo de Jorge Amado, por exemplo, é lembrada em Desmedida pela sua trilha sonora, em que a música tema, nas palavras do autor angolano, era como um "novo rasgo de ironia, cantava essa música deliciosa que nos trata a todos por camaradas e enquadrava perfeitamente na nossa novel e militante cena nacional" (CARVALHO, p. 69).

Nesta senda, Ruy Duarte de Carvalho chama a atenção para "uma geração de muitos e bons músicos brasileiros que andavam [...] a dizer coisas que se adaptavam também perfeitamente a situações e a constrangimentos que para alguns de nós não havia maneira de não estar a ver que eram também cada vez mais nossos, embora Angola estivesse a fazer uma revolução" (CARVALHO, p. 69-70). Talvez, seja a resistência ao autoritarismo presente nas letras das músicas compostas na época da ditadura civil-militar no Brasil, que tenham gerado uma identificação pelos angolanos com as canções da música popular brasileira, como também, a presença de uma abordagem social na representação de figuras humanas excluídas ou silenciadas. 
Entre tantos temas abordados em Desmedida, como a última parte, da segunda metade: "Os agrestes nordestes", em que vários personagens históricos e populares são resgatados, Carvalho apresenta parte da trajetória do cangaço no sertão nordestino, trazendo Lampião e seu bando como personagens fundamentais nesse processo de luta. E segundo o autor, nos dias de descanso entre costuras e bailes, Lampião era "poeta também nas horas", provável compositor de "MuIher rendeira", canção cantada pelo cangaceiro e seu bando em muitas lutas.

Notícias de um Brasil popular chegavam aos angolanos pelas composições de Paulo Vanzolini, em seus versos sobre a boemia paulistana com referências espaciais reais da cidade, assim como, músicas cantadas pela voz de Elis Regina e de Roberto Carlos. Carvalho lembra também, da viagem que Chico Buarque faz com outros músicos para Angola² , em 1980, com o intuito de comemorar os cinco anos de independência do país, e que ficou registrada na música "Morena de Angola". Segundo o autor angolano, a canção apresenta "essa glória que é a mulata de chocalho na canela, da Catumbela" (CARVALHO, p. 70). Sem dúvida, uma homenagem à mulher angolana tanto pela sensualidade feminina quanto por uma militância política, como indicam os versos finais: "minha camarada do MPLA" (sigla do Movimento Popular de Libertação de Angola).

2 O Projeto Kalunga, foi idealizado pelo produtor e diretor Fernando Faro, diante do convite recebido por Chico Buarque, por autoridades angolanas, para fazer um show em Angola no ano de 1980. Ao ser convidado para dirigir o show, Faro teve a ideia de transformar a apresentação em um projeto maior, convidando outros artistas brasileiros a se solidarizarem com os angolanos que lutaram pela sua liberdade. Participaram deste espetáculo, além de Chico Buarque, Milton Nascimento, Martinho da Vila, Dona Ivone Lara, entre muitos outros. Segundo o site Museu Afro Digital, que apresenta uma pesquisa em andamento sobre o Projeto, um grupo de 65 pessoas, entre técnicos, produtores e artistas, fizeram parte do grupo que se apresentou em Luanda, Benguela e Lobito. 
REVISTA CRIOULA N ${ }^{\circ} 20-2^{\circ}$ SEMESTRE/2017

\section{Desfecho}

"Tem mesmo rumos que o destino impõe. Resta, pois, fazer a mala e precipitar um remate" (CARVALHO, p. 389), dessa forma tem início a última parte do livro, denominada Fecho, na qual, o autor explicita a bibliografia que o inspirou ao longo da vida e da jornada entre São Paulo, Luanda, São Francisco e a volta para Angola. Assim, o leitor tem acesso a uma bibliografia comentada pelo autor angolano, que começa por Voyage atlantique, de Ernst Jünger, escritor e filósofo alemão, de quem confessa ser leitor compulsivo, assim como de João Guimarães Rosa. A exploração entomológica realizada na descida de barco pela costa brasileira relatada por Jünger é o que fascina o antropólogo Ruy Duarte de Carvalho.

$\mathrm{E}$ aos poucos o leitor é informado dos livros que o acompanharam desde Luanda, como Capítulos de história colonial, de Capistrano de Abreu, "por imperioso e misterioso impulso", e de outros que foi obtendo pelo caminho, quando na passagem por Paris juntou "noutro impulso premonitório, D’oultremer à índigo, de Blaise Cendrars" às duas "cômodas e leves" edições de bolso de Edgar Morin, segundo Carvalho, seu "velho mestre", Amour, poésie, sagesse, e Dialogue sur la nature humain, com Boris Cyrulnik. Leituras reveladoras de "percepções, expressões, entendimentos e impasses revelados pelo curso da expansão geográfica e cultural europeia, e da modernidade civilizacional, ao longo dos últimos séculos" (CARVALHO, p. 390).

Carvalho encontra em um sebo paulista, "uma volumosa segunda edição, de 2001, de $A$ aventura brasileira de Blaise Cendrars, muito iconografada e recheada de textos" (CARVA- 
LHO, p. 394) que somada à Paulística etc., de Paulo Prado e mais dois volumes sobre a história da cidade de São Paulo levou-o ao encontro de memórias sobre os bandeirantes e literaturas fundadoras. E para "entender melhor o Brasil" autores contemporâneos como Lilia Moritz Schwarcz e Angela Marques da Costa, Helena Bocayuva, Flora Süssekind e Evaldo Cabral de Mello. Bem como História dos índios no Brasil, organizado por Manuela Carneiro da Cunha e Os índios nas cartas de Nóbrega e Anchieta, de Filipe Eduardo Moreau. Em sua bibliografia criticamente comentada, acrescenta o "gratificante feito, assim, de acerto editorial" sobre a $26^{a}$ edição, de 1955, de Raízes do Brasil, de Sérgio Buarque de Holanda, prefaciada por Antonio Candido (CARVALHO, p. 394).

Em sua pesquisa de campo, Carvalho mergulhou paralelamente em uma vasta bibliografia. Percorrendo autores e edições recentes sobre João Guimarães Rosa, "depois de ter andado pelo São Francisco superior a relê-lo quase todo, impus-me, para poder prosseguir viagem" (p. 398) volumes como O Brasil de Rosa, o amor e o poder, de Luiz Roncari, de 2004, O recado do nome, de Ana Maria Machado, de 2003 e na $4^{a}$ edição de 2002, o texto "O homem dos avessos", de Antonio Candido. Já sobre "os passados do rio São Francisco" volta-se para Richard Burton, Teodoro Sampaio, Saint-Hilaire e Wilson Lins com seu $O$ médio São Francisco, uma sociedade de pastores e guerreiros e ainda Memórias da Dinda e O último canto do cisne, de Joana Camandaroba, bem como outros que segundo o autor, não leu, mas, ouviu contar.

Neste percurso bibliográfico no confronto entre "paisagens físicas" e "paisagens literárias" encontra-se um volume 
de Os sertões, de Euclides da Cunha, que Carvalho adquiriu em Luanda em 1968, como indica a "escrita a lápis, na primeira página de guarda" (p. 400). E sobre Euclides da Cunha limitou-se ao opúsculo Atualidades de Euclydes da Cunha, de Gilberto Freyre e ao que encontrou "referido pelo tradutor alemão de Os sertões, Berthold Zilly", para não se "ver envolvido na evocação do drama pessoal da vida sem jeito de tamanho autor" (p. 400). Carvalho adentrou ainda por sebastianismos e messianismos por via de Roger Bastide e Maria Isaura Pereira de Queiroz, e sobre Lampião e sua época, por Billy Jaynes Chandler e Frederico Pernambucano de Mello. Bem como "sobre o tempo dos holandeses" em uma vasta bibliografia que reflete o alcance dos temas abordados em Desmedida.

Destarte, o projeto de Ruy Duarte enveredou por muitos caminhos e revelou um país que mantém uma cultura de fronteira como condição. Mas, não a fronteira com limites, e sim,

Esse espaço brasileiro que embora perfeitamente definido pela geografia política estabelecida, fixada e sedimentada, escapa todavia a um controle efetivo por parte do poder que invoca soberania sobre ele [...]. Identificada assim uma perfeita singularidade para o Brasil de agora. (CARVALHO, p. 83-84)

A relação emocional que o autor mantém com o Brasil perpassa a narrativa, com uma certa preocupação até, expressa no texto, de não ultrapassar limites. Sejam eles o de cair em uma subjetividade, ou de querer "explicar" o Brasil para brasileiros, "tenho andado a ver se o explico é para mim mesmo" (CARVALHO, p. 203). Ruy Duarte de Carvalho tem o 
cuidado de não cair na armadilha do olhar estrangeiro de uma visão pré-fabricada sobre o outro. Os relatos demonstram o alcance do equilíbrio entre uma visão/percepção por vezes apaixonada, por tanto, mais próxima, e outra mais distanciada, e assim, crítica.

O autor acaba por recolher e atravessar "tanta informação" e "tanta emoção" ao meter-se

Nestas viagens, uma através do São Francisco e outra através da produção de um livro, com a intenção e a certeza quase de que no fim delas haveria de alcançar alguma noção mais precisa de um Brasil que mexe comigo desde que me sei gente. (CARVALHO, p. 203)

O mais interessante nessa viagem, talvez, seja a relação sul-sul, em que não ocorre predomínio de uma visão caricatural ou exótica do país por um estrangeiro. Não há uma ideia pronta comum aos exploradores ocidentais. Pois, nas palavras do próprio autor,

$E$ de qualquer maneira, a viagem que tenho pela frente, vou fazê-la de fato porque ao longo da vida sempre fui mantendo o Brasil como paixão, ancorado numa condição periférica de angolano excêntrico em que apesar de tudo consegui manter-me coexistindo sempre com meia dúzia de referências, nomes de autores, personagens brasileiras e painéis inteiros de paisagens que confundi com as minhas. (CARVALHO, p. 70-71) 


\section{REFERÊNCIAS BIBLIOGRÁFICAS}

BITTENCOURT, Marcelo. Conexão Brasil. Revista de História, 10 dez. 2008. Disponível em: <http://www.revistadehistoria.com.br/secao/capa/conexao-brasil>. Acesso em: 25 mar. 2015.

CABAÇO, José Luís. Gentes, agentes e agendas... a propósito de uma leitura de Actas da Maianga. Revista Setepalcos, Coimbra, 2006 p. 40-43.

CARVALHO, Ruy Duarte de. Desmedida: Luanda, São Paulo, São Francisco e volta. Rio de Janeiro: Língua Geral, 2010 (Coleção Ponta de Lança).

MUSEU AFRO DIGITAL RIO DE JANEIRO. Exposição: Memória do Projeto Kalunga. Disponível em: <http://museuafrodigitalrio.org/s2/?work=memoria-do-projeto-kalunga> . Acesso em: 13 jun. 2015.

SANTILLI, Maria A. Paralelas e tangentes: entre literaturas de língua portuguesa. São Paulo: Arte\&Ciência, 2003 (Coleção Via Atlântica, 4).

Submissão: 19/08/2017

Aceite: $26 / 11 / 2017$ 